Aletria, Belo Horizonte, v. 28, n. 1, p. 147-161, 2018

\title{
A (de)/(re)composição autobiográfica do corpo na poética de Começo, de Nathalie Quintane
}

\section{The autobiographic (de)/(re)composition of the body in the poetry of Começo, by Nathalie Quintane}

\author{
Lívia Ribeiro Bertges \\ Universidade Federal de Mato Grosso, Cuiabá, Mato Grosso / Brasil \\ livia.bertges@gmail.com \\ Vinicius Carvalho Pereira \\ Universidade Federal de Mato Grosso, Cuiabá, Mato Grosso / Brasil \\ viniciuscarpe@gmail.com
}

Resumo: O presente artigo apresenta uma leitura dos textos que compõem a série "Começo" na obra homônima de Nathalie Quintane, a qual se situa a meio do caminho entre a autobiografia e a poesia. Pretende-se aqui compreender como a composição, decomposição e recomposição do corpo humano é estruturada no livro como proposta de uma anatomia poética do $\mathrm{eu}$. Nesse processo, delineiam-se como linhas de força o erótico e o abjeto como instâncias em que o eu se reconhece - e se desafia - como corpo e linguagem. Como balizas teóricas que respaldem tal leitura, elegem-se aqui as noções de pacto autobiográfico, de Lejeune (2014); de erotismo e escritura, de Barthes (1987); e de abjeção e significação, de Kristeva (1982). Destaque-se, por fim, que, como autobiografia e poesia, Começo propõe simultaneamente um percurso de formação e de deformação da primeira pessoa discursiva, como vias contrárias que se encontram no texto de Quintane.

Palavras-chave: corpo; autobiografia; Nathalie Quintane.

Abstract: This paper presents a reading of the texts that make up the "Começo" series in the work Começo, by Nathalie Quintane, which is halfway between autobiography and poetry. We herein aim to understand how the arrangement, disarrangement and 
rearrangement of the human body is structured in the book as a poetic anatomy of the self. In this process, two main issues come forth: the erotic and the abject as instances where the $I$ recognizes and challenges itself as body and language. We have, thus, chosen as theoretical pillars to support our analysis: the concepts of autobiographical pact, by Lejeune (2014); eroticism and writing, by Barthes (1987); and abjection and meaning, by Kristeva (1982). Finally, as both autobiography and poetry, Começo simultaneously proposes a journey where the first person is formed and deformed in controversial paths that meet in Quintane's text.

Keywords: body; autobiography; Nathalie Quintane.

\section{Introdução}

Começo (2004), obra da autora francesa contemporânea Nathalie Quintane, constitui-se de um montante de experimentações poéticas, cujo enfoque é centrado na (de)/(re)composição de corpos por meio da escrita, em uma busca pelos processos de constituição de si na carne e na linguagem. Tal entrelaçamento entre corpo e palavra torna-se ainda mais patente quando, na capa, logo após o título, vê-se escrito: [autobiografia]. Tal designação circunscreve um gênero discursivo e, portanto, um conjunto de temas e procedimentos retóricos, mas aparece modalizada na capa do livro de Quintane por expedientes tipográficos. Entre colchetes, em itálico e com inicial minúscula, não se trata aqui de autobiografia como relato de um eu que se supõe inteiriço e narra uma pequena epopeia de si, com começo, meio e fim. Começo, como o próprio título sugere, é um texto que autobiografa a busca de identidade da autora, mas que perscruta também uma gênese do verbo, em que o eu da enunciação e o eu do enunciado se (de)/(re)compõem nos fragmentos que estruturam a obra. Se todo relato de si é feito como resposta a uma pergunta (ainda que jamais enunciada), como afirma Butler, ${ }^{1}$ o livro de Quintane talvez responda à pergunta: onde começa e termina o corpo que fala, cujos limites físicos e ontológicos se constroem por um corte junto à linguagem?

Para dar conta de si como texto - o sujeito como mais um texto na rede paragramática ${ }^{2}$ que Começo estabelece entre os fragmentos poéticos -, Quintane constrói sua autobiografia por uma sucessão de formas

\footnotetext{
${ }^{1}$ Cf. BUTLER. Dar cuenta de sí mismo: violencia ética y responsabilidad.

${ }^{2} \mathrm{Cf}$. KRISTEVA. Introdução à semanálise.
} 
breves: pequenos excertos descritivos, formulados em até cinco linhas; poemas curtos de alta carga lírica e versos livres; diminutos contos de ares surrealistas. À multiplicidade de gêneros corresponde uma variedade de tipografias na página, com letras de fonte e tamanho diversos, diferentes espaçamentos entrelinhas, impressão ora no centro, ora no topo, ora no pé da folha. Quase aos moldes de um diário, as ideias, imagens e estruturas gráficas alternam-se ao correr livre da mão, que transpõe para a espacialidade da página a busca estética e ética de toda autobiografia.

Tal hibridação de gêneros discursivos se reflete até mesmo na ficha catalográfica, que apresenta os seguintes descritores para a obra: "memórias autobiográficas", "poesia francesa" e "reminiscências poéticas". Entre o memorialístico e o poético, estabelece-se de modo peculiar o pacto autobiográfico ${ }^{3}$ que o leitor firma com Quintane. Como autobiografia, espera-se que o leitor encontre um relato de si da autora, em que os sujeitos da enunciação e do enunciado convirjam para uma narrativa de fundação de uma identidade. Por outro lado, como obra poética, essa narrativa de si se dá não por um enredo que encadeie logicamente cenas em primeira pessoa. Em vez disso, Começo apresenta séries poéticas como "Começo", "Pequeno(a)", "Colégio", "Come" e "Crise", as quais vêm numeradas (em "Começo 1", "Começo 2", etc.) e às vezes acompanhadas de um título (como em "Pequeno 2. Eczema").

Algumas dessas séries se constroem pela repetição temática; outras, por uma reiteração retórica, em que determinadas estruturas frasais são reincidentes nos pequenos textos. Esses fragmentos poéticos, ordenados por uma sintaxe de números e repetições, compõem a macroestrutura da obra, em que se vê uma tentativa de recompor memorialisticamente um eu a partir de reminiscências esgarçadas no tecido da linguagem. Os títulos de cada série, se lidos em uma cadeia linear, podem ainda indicar uma lábil cronologia, em que o sujeito que começa a ser é primeiro pequeno, depois vai para o colégio, entra e come no mundo social das refeições em família e, uma vez em sociedade, reconhece-se em crise diante das mais diversas situações em que sua subjetividade é confrontada.

No âmbito dessa obra, o presente artigo indaga como os quatro textos da primeira série do livro, também intitulada "Começo", propõem um (des)/(re)monte corporal por meio da escritura, em que a busca pelo "começo", ou pela gênese identitária, se revela uma erótica e uma abjeção verbais.

${ }^{3}$ Cf. LEJEUNE. O pacto autobiográfico. 


\section{Uma autobiografia de cortes: talhos poéticos na carne}

Em Começo, o subtítulo [autobiografia] clama por um referencial teórico específico, aqui discutido à luz o pensamento de Philippe Lejeune. Em O pacto autobiográfico, ${ }^{4} \mathrm{o}$ autor problematiza a possibilidade de uma definição única para a autobiografia: "o sucesso da palavra 'autobiografia' está sem dúvida ligado à ambiguidade ou à indecisão que o termo permite, ao novo espaço de leitura e interpretação que possibilita, às novas estratégias de escrita que pode designar". 5

Conforme as distintas cargas semânticas de que o termo pode se revestir, alarga-se ou estreita-se o universo de práticas discursivas que ele pode recobrir. No caso da literatura contemporânea, em que os relatos de si se tornam cada vez mais populares - talvez para construir uma mínima coerência identitária frente a um mundo progressivamente mais difuso e lábil $-{ }^{6}$ devêm ambíguos também os textos a serem ditos como autobiográficos. Permeando zonas limítrofes da escrita literária, obras como Começo só podem ser ditas autobiográficas se o termo for tomado lato sensu, uma vez que, em diversos fragmentos, sequer se ouve uma voz em primeira pessoa, a qual parece eclipsada por um olhar anterior à constituição da subjetividade:

\section{Começo 2}

Ele nasceu com uma abertura na bochecha. Quando ele come, tem sempre duas possibilidades, mas a colher não hesita, ela se introduz de preferência pela abertura suplementar, que, perto da garganta, dirige mais rápido os alimentos mastigados para baixo. ${ }^{7}$

Narrando o nascimento de um "ele" estranho, dotado de duas cavidades por onde o alimento possa ser introduzido, a voz narrativa não revela qualquer choque ou surpresa diante da criatura surrealista. Em terceira pessoa, o breve conto relata com distanciamento a vida de alguém com uma fenda suplementar, adotando uma neutralidade enunciativa estranha ao gênero autobiográfico e mesmo à boa parte do que se considera lírico.

\footnotetext{
${ }^{4}$ LEJEUNE. O pacto autobiográfico, p. 57.

${ }^{5}$ LEJEUNE. O pacto autobiográfico, p. 63.

${ }^{6} \mathrm{Cf}$. ARFUCH. O espaço biográfico.

${ }^{7}$ QUINTANE. Começo, p. 15.
} 
Por outro lado, se tomados em conjunto, os textos que compõem Começo revelam um relato da formação desse sujeito, que ora narra a distância o que vê do mundo, ora se representa no mundo narrado. Nesse processo, a terceira pessoa dos textos iniciais vai gradativamente sendo substituída pela primeira, expediente retórico autobiográfico por definição. Assim, na série formada por "Começo 1", "Começo 2", "Começo 3" e "Começo 4", as marcas pronominais, que balizam o ponto zero da enunciação, passam gradativamente da neutralidade à pessoalidade, evidenciando uma constituição discursiva do sujeito que vai se formando à medida que escreve. Desse modo, em "Começo 4", último texto da primeira série do livro, o sujeito da enunciação já aprendeu a dizer $e u$ e a falar da sua própria gênese, como se nota em sua primeira frase: "Porque não nasci com uma colher na boca, é preciso a cada vez que ela chegue de fora". 8

Se tanto "Começo 2" quanto "Começo 4" têm em suas primeiras frases o relato do nascimento de duas criaturas distintas - um ele e um eu -, apenas um pacto autobiográfico poético - diferente de suas versões em narrativas em primeira pessoa mais tradicionais - pode ensejar a leitura do livro como um todo autobiográfico. Nesse processo, a autobiografia de Quintane empreende a construção de um espaço de leitura em que as tensões entre o sujeito e o objeto - basilares da entrada no simbólico e na linguagem - são reintegradas na superfície textual.

No caso de Começo, tais tensões se tornam ainda mais acirradas. Afinal, quais são as cláusulas do contrato de leitura de um pacto autobiográfico poético? Se Maurice Blanchot (1984) afirmara que a poesia é uma travessia em que a primeira pessoa autoral se dissolve em uma terceira, e o poético nasce lá onde não mais existe o sujeito, é como travessia de retorno, então, que Começo deve ser lido. À medida que o livro avança e as séries poéticas se alternam, o foco discursivo em terceira pessoa vai dando lugar à primeira. $\mathrm{O}$ pacto de leitura da autobiografia poética de Quintane é, assim, contrato de viagem de retorno ao eu - e não para longe dele - como pensara Blanchot (1984).

O leitor adentra o livro de Quintane, deparando-se, de pronto, com os primeiros e perturbadores parágrafos de "Começo 1":

${ }^{8}$ QUINTANE. Começo, p. 23. 
Exceto um cirurgião operando a si mesmo, como H. a caminho do polo Norte abriu ele mesmo sua barriga, segurando as pinças de vez em quando na boca enquanto se localiza, é dado a poucos cortar e levar à altura dos olhos um de seus próprios pedaços.

[...]

Exceto um espeleólogo sem lanterna, tal como B. em busca pela décima-quarta vez da fonte do Sorgue, e não tendo pensado em despejar antes na água o E 414 que permite segui-la, é dado a poucos tocar assim continuamente a escuridão. ${ }^{9}$

A lógica da fragmentação, que preside a construção da macroestrutura do livro, é replicada para a estrutura interna de "Começo 1": os dois parágrafos acima são os únicos que constam na página 11 do opúsculo, mas, em vez de serem diagramados um logo abaixo do outro, são separados por grande área em branco na página (no presente artigo, substituída nas citações por “[...]”, por questões de espaço). Impressos um no topo e o outro aos pés da folha, os parágrafos graficamente alheados entre si, dizem de um sujeito em vias de constituição e que ainda não diz eu, vendo seu corpo - físico e textual - como conjunto de estilhaços. Ao passo que o pacto autobiográfico garante um mínimo de coesão à coleção de séries do livro, lido como um poético relato do eu, dentro de cada série a coesão é garantida por expedientes retóricos, de modo que a unidade aí advém da língua - simbólico a partir do qual todo sujeito emerge. No caso de "Começo 1", o expediente retórico, que interliga os parágrafos e encadeia-os como significantes em um discurso do eu emergente, é a reiteração de estruturas sintáticas ao longo dos oito parágrafos: a preposição acidental "exceto" logo ao início; uma conjunção comparativa após a primeira vírgula; e, já próximo ao final, o sintagma verbal "é dado a poucos". Tal repetição não só engendra ritmo, mas cria também identidade, que é tanto fônico-sintática quanto ontológica, permitindo a gênese de um sujeito que se forma pela reiteração de padrões observáveis. Esse nascimento se revela ainda no plano do conteúdo do primeiro parágrafo, uma vez que o cirurgião que opera a si mesmo e abre a própria barriga é alguém que faz uma cesariana em/de si mesmo e, em vez de sacar um bebê, leva "à altura dos olhos um de seus próprios pedaços".

Cortando o corpo somático como quem corta o corpo textual, o cirurgião é análogo ao espeleólogo que contempla a escuridão de si,

${ }^{9}$ QUINTANE. Começo, p. 11. 
o qual, por sua vez, é análogo a cada um dos outros personagens, cujo nascimento assiste Nathalie Quintane em "Começo 1", enquanto gesta a si mesma em sua uterina caverna poética.

Nesse processo, corpo e texto são revestidos de uma materialidade que os valoriza como superfícies táteis, sobre as quais pode correr a pena que escreve o diário íntimo, ou o bisturi que corta e escava a pele do sujeito. A meio caminho entre o erótico e o abjeto, as imagens de incisão e escalavradura, reincidentes nos trechos de "Começo 1", aproximam a escrita do desejo, ${ }^{10}$ força motriz do sujeito que busca aquilo que o funda, porque perdido na castração e na sua entrada no simbólico.

Numa enumeração que vai da escrita ao gozo, passando por numerosos lugares do corpo, as palavras assumem diferentes tópicas e incorporam-se como gestos no jogo "escrita-leitura". Fundamentando a prática da escrita por meio do conhecimento do corpo que escreve, o poético em Quintane se dá pelas incisões que fendem a pele, dividem os significantes, racham sujeito e objeto.

Assim, Começo se constrói da decomposição em partes desse corpo - físico e textual -, negociando em negatividade com a emergência de um eu. Oscila, assim, na corda bamba da construção de memória individual ou coletiva, em primeira e em terceira pessoa - só para tentar entender um corpo, isto é, (re)compor um corpo (des)composto, como se nota nos dois próximos parágrafos de "Começo 1":

Exceto um biólogo perdido por acaso num departamento de física atômica, tal como D. apoiando os seus olhos no túnel do microscópio, é dado a poucos de a esse ponto estremecer descobrindo como a matéria se decompõe.

$[\ldots]$

Exceto uma enfermeira julgada incapaz por uma outra enfermeira, e reservada por consequência às tarefas mais ingratas, limpando os doentes lavando-os sem descanso, é dado a poucos testar tantas vezes as qualidades intrínsecas da pele. ${ }^{11}$

Observando por um microscópio a matéria que se decompõe, ou esfregando-a com produtos hospitalares, os anônimos personagens veem a substância, que era e em breve não mais será, num processo inverso ao

${ }^{10}$ Cf. BARTHES. O prazer do texto.

${ }^{11}$ QUINTANE. Começo, p. 12. 
da narradora, cuja subjetividade ainda não era, mas vai se construindo no discurso e, em breve, será. Assim, a autobiografia se constrói porque, por meio do texto poético, à autora é dada (ainda que a poucos o seja, como repete o poema) a chance de "estremecer descobrindo como a matéria se decompõe" ou "testar tantas vezes as qualidades intrínsecas da pele".

Barriga aberta, caverna explorada, matéria devassada, pele esfregada: as imagens que esses parágrafos encerram revelam uma reincidência dos traços semânticos da incisão e da fricção, as quais viram para fora o de dentro dos corpos, num processo erótico de gênese que instala, por meio de uma fenda, uma oposição entre o interno e o externo pela qual todo sujeito se constitui.

Como diz a teoria do texto: a linguagem é redistribuída. Ora, essa redistribuição se faz sempre por corte. Duas margens são traçadas: uma margem sensata, conforme, plagiária (trata-se de copiar a língua em seu estado canônico, tal como foi fixada pela escola, pelo uso correto, pela literatura, pela cultura); e uma outra margem, móvel, vazia (apta a tomar não importa quais contornos), que nunca é mais do que o lugar de seu efeito: lá onde se entrevê a morte da linguagem. Essas duas margens, o compromisso que elas encenam, são necessárias. Nem a cultura nem a sua destruição são eróticas; é a fenda entre uma e outra que se torna erótica. ${ }^{12}$

$\mathrm{Na}$ fenda entre o sentido e a desrazão, entre uma interioridade e uma exterioridade do eu que surge no texto, o sujeito vai se diferenciando do objeto pela entrada no simbólico por meio de uma série de cortes. No entanto, para além do gozo, não se pode perder de vista aqui a ameaça que o abjeto postula, à espreita na referida fenda. Afinal, tanto a barriga aberta do cirurgião quanto a pele purulenta do doente são imagens repulsivas (mas também algo eróticas), porque trazem à superfície do corpo o que só lhe deveria pertencer como interioridade, criando a talho um orifício que é genitália, porque erótico, mas também cloaca, porque abjeto.

Fazendo vacilar as fronteiras do corpo, o abjeto instala medo e ao mesmo tempo desejo, na medida em que lembra ao sujeito a noite imemorial anterior à sua constituição no simbólico, quando sujeito e objeto eram ainda uma massa indivisa e informe, ${ }^{13}$ como o pus que vai se acumulando na pele fistulosa. Assim, ao lado do eu, que se constrói em Começo, mora sempre o perigo da dissolução novamente em uma

12 BARTHES. O prazer do texto, p. 11.

${ }^{13}$ Cf. KRISTEVA. Powers of Horror: an Essay on Abjection. 
não pessoa, seja pelas vias do poético, seja pelas do abjeto. Ou por uma poética do abjeto, como a das páginas desse livro.

A conflituosa relação entre um corpo indiviso e uma coleção de fragmentos corpóreos, entre um dentro e um fora em que se recortam os significantes do $e u$, é evidenciada também nos primeiros três parágrafos de "Começo 3":

\section{Começo 3}

Numerosos lugares do corpo, invisíveis ou dissimulados (as axilas, a parte interna dos braços, a parte interna das coxas, entre as nádegas, a sola dos pés), são sensíveis demais para serem vacinados.

Ou então é a situação deles que o fragiliza, e se estivessem virados para fora, eles ganhariam espessura e pátina.

A sola dos pés fornece aqui um mal exemplo, já que pode adquirir a solidez de uma verdadeira crosta em certos pontos, ao passo que em outros ela parece tão fina quanto papel pelure. ${ }^{14}$

Fatiado e cartografado, o corpo aqui já não é explicitamente de uma terceira pessoa, mas não é ainda atribuído à primeira. Trata-se do corpo como objeto fragmentado, cujas partes se encontram obliteradas e mesmo suspensas (ou interditas) entre parênteses. Como coleção de peças, esse corpo possui "lugares", e não "membros", o que replica para o somático o trabalho com a espacialidade que preside à diagramação elaborada de Começo.

Mapeando zonas sensíveis do corpo, o eu se constrói por metonímia dessas partes desconexas e escondidas, tão sensíveis quanto a linguagem que as evoca como interditos que não se vacinam, não se nomeiam em público, não se tocam, exceto no ato erótico, em que esses espaços internos se tornam superfícies a serem acariciadas. Ambos os espaços, da escrita e do corpo, sofrem a entrada no simbólico, doem ao serem "vacinados", inoculados, penetrados.

As axilas, a parte interna dos braços, a parte interna das coxas, as nádegas, são lugares marcados pelo sema da interioridade, o que, por extensão, lhes atribui uma carne mole, macia e sensível, onde a perfuração da agulha seria sempre mais dolorosa. Por sua vez, a sola do pé, exterioridade por excelência que garante o contato entre o sujeito e

${ }^{14}$ QUINTANE. Começo, p. 19. 
o real-objeto que pisa, é tradicionalmente entendida como dura, áspera, casca que engrossa e racha à progressão que o sujeito se constrói e marcha. No entanto, no poema acima, a extremidade do pé não é homogênea: composta por pontos de diferentes espessuras, ela é ao mesmo tempo crosta e papel pelure, dureza e maciez em "Começo 3". O corpo (de)/(re) composto não sugere, pois, uma anatomia exata, e sim camadas múltiplas de sentido, do eu ou de pele na sola dos pés.

Frágil parece a princípio esse corpo, mas tal perspectiva é invertida pelo conectivo "ou então", no segundo parágrafo, ao questionar a posição de cada parte desse organismo, pensando na possibilidade de uma mudança de local, uma (re)composição do corpo como em jogo de criação de um novo ser. Anatomista que disseca o corpo, o eu que se relata em Começo sonha ainda com operações de translação, virando o de fora para dentro e vice-versa, expondo ao mundo as carnes flácidas e introjetando a carapaça endurecida. Ao virar papel pelure, o pé vira película transparente e porosa, não mais barreira e sim mucosa. Voltando para fora suas carnes mais macias, o corpo descomposto é recomposto como máquina de puro desejo e gozo, em que o eu se reconhece pelo avesso.

Lendo ainda o excerto de "Começo 3" à luz de um pacto autobiográfico poético, o vocábulo "vacina" instala uma ambiência infantil na prosa poética, não só evocando cenas do terror da criança ante à agulha, mas também como exercício de entendimento do próprio corpo que as crianças experimentam diante do espelho. Bem como esclarece Calligaris, "Narrar-se não é diferente de inventar-se uma vida. Ou debruçar-se sobre sua intimidade não é diferente de inventar-se uma intimidade. $\mathrm{O}$ ato autobiográfico é constitutivo do sujeito e de seu conteúdo". ${ }^{15}$ Ao decompor o corpo e recompô-lo em imagem poética, Quintane narra a si e inventa seu corpo físico e textual, como se observa também em outra passagem de "Começo 3":

Aprendemos mais tarde a distinguir-nos por pedaços: dor no cólon, dor no intestino, dor no fígado; a bile toma rapidamente importante dimensão através do bilioso, o amarelo, e tudo o que se relaciona com isso: se cuspimos amarelo depois, não é mais como antes. Entretanto isso não perde jamais completamente seu carácter surpreendente.

${ }^{15}$ CALLIGARIS. Verdades de autobiografias e diários íntimos, p. 49. 
Reconhecemos nossa bile, desta vez intacta e dentro da sua bolsa, pendurada ao órgão, num coelho - não é bile de coelho ou a bile do coelho, é a bile. Despinicado e virado pelo avesso, com a pele escorregando pela cabeça, depois aberto, ela sai. ${ }^{16}$

A voz enunciadora mais uma vez remonta à distinção (e, portanto, à significação) corporal em "pedaços", tomando o corpo como estrutura a ser entendida, compreendida e sentida por dissecação. Nesse procedimento, é o sofrimento que guia o bisturi, delimitando regiões doloridas do trato digestivo, assim como a dor da vacina identificava axilas, parte interna de braços, coxas e nádegas no início de "Começo 3".

Fazendo da dor uma infecção, a bile é secretada (como secreção, mas também como segredo das profundezas do corpo) e esparramada por toda a cadeia de significantes e de órgãos. Sempre surpreendente, como todo segredo que vem à tona, a bile do sujeito autobiográfico poético aqui escorre pela boca, pela pele, pela cabeça, como fluido erótico ou secreção abjeta que vem à tona quando o sujeito se perde, ainda que por um instante, no objeto, por meio do gozo orgástico ou da excreção hórrida.

Nessa autobiografia às avessas, em que Nathalie Quintane fala de um começo ameaçado o tempo inteiro por um fim, o corpo se revela um espaço duplamente escatológico. Skatós era o termo grego para designar o excremento; éskhatos, o termo grego que nomeava o que ocorreria após o fim do mundo. Na evolução das línguas latinas, ambos os termos confluíram para palavras idênticas - "escatologia" -, designando a secreção e o pós-apocalíptico, em uma ambivalência que a bile pode bem nomear.

Nesse sentido, ler o bilioso texto de Começo ou o bilioso corpo da Quintane, que se constrói na escritura, requer falta de asco, mas também requer fé (instância última em que reside a suposição de que as coisas, os discursos, ou os sujeitos possam ter um sentido). De acordo com Lejeune, "Se podemos dizer que a autobiografia se define por algo que é exterior ao texto, não se trata de buscar, aquém, uma inverificável semelhança com uma pessoa real, mas sim de ir além, para verificar, no texto crítico, o tipo de leitura que ela engendra, a crença que produz". ${ }^{17}$

A crença em que se afirma o pacto autobiográfico é a mesma que preside a assinatura de quaisquer duas partes em um contrato; é, ainda,

${ }^{16}$ QUINTANE. Começo, p. 20.

${ }^{17}$ LEJEUNE. O pacto autobiográfico, p. 55. 
inerente à linguagem poética, que só pode ser tomada como performativa, isto é, como agência sobre o mundo, também por uma crença - ou um princípio interpretativo. No caso de Começo, é em "Começo 4", transcrito na íntegra a seguir, que esse princípio interpretativo se torna mais evidente, delineando-se já de maneira explícita a primeira pessoa gramatical e articulando-se, por relações de causalidade, a morfologia do sujeito poético.

\section{Começo 4}

Porque não nasci com uma colher na boca, é preciso a cada vez que ela chegue de fora.

Porque não nasci com os cabelos grossos como cabos, o espaço entre dois dentes de pente passa raramente de um milímetro.

Porque o meu nariz não cresceu para dentro, é o fora que eu respiro.

Porque não tenho buraco no pescoço, a minha voz sai pela boca. Porque minhas mãos acabam em dedos, as mangas dos pulôveres têm a ponta cortada.

Porque não nasci com a cabeça grudada, posso olhar à direita, e à esquerda.

Porque o meu pé veio no final da minha perna, não ando pelo meio. Porque os meus dentes saem separados, eu os perco um a um.

Porque os meus ossos crescem, as camas não têm todas o mesmo comprimento.

Devido à epiderme que por toda parte me recobre, sou sensível também nos cotovelos.

Porque meus dois olhos estão colocados a uma distância igual das bordas da minha cabeça, as lentes dos óculos, bem como as hastes, são de tamanho idêntico.

Porque o lugar das mãos é na ponta dos braços, à direita e à esquerda, os bolsos das roupas não estão nunca situados na parte de baixo das calças.

Devido ao nervo que o retém por detrás e que não vejo, há poucos riscos que meu olho caia. ${ }^{18}$

Uma série de 11 respostas a questões imaginárias é colocada à vista. O uso recorrente de "porque" e da variante "devido a" indica relações de causalidade expressas sistematicamente em poucas linhas,

${ }^{18}$ QUINTANE. Começo, p. 23-24. 
como se esgotassem a possibilidade de qualquer outro questionamento sobre a morfologia do corpo. Nesse jogo, as superfícies palpáveis são exploradas: "boca", "cabelos", "nariz", "pescoço", "dedo", "cabeça", "perna", "dentes", "ossos", "olhos" e "mãos" - como em um quebracabeça, cujas peças estão soltas à procura de pares para formarem sistemas ou aparelhos fisiológicos. Na tentativa de mapear essas partes do corpo e suas conformações, constrói-se o eu como bricolagem, isto é, como recolha de fragmentos de si. Tal prática é, portanto, análoga ao processo da escritura, a qual "[...] precisa do descontínuo, o descontínuo é de algum modo a condição orgânica de seu aparecimento". ${ }^{19}$

A repetição da estrutura "não nasci com” em alguns dos parágrafos recobra uma data precisa do desenvolvimento humano, o nascimento como começo que intitula a obra. Mas, ao construir-se por negação, o eu nascente (e "narrante") se entende por oposição às formas como não nasceu, formando-se sujeito pela recusa ao abjeto do nariz para dentro, do pescoço esburacado ou da perna com a pele pelo meio. Concomitantemente, o uso recursivo do pronome possessivo "meu" demarca o corpo como pertencente à voz subjetiva, o que não se identifica em "Começo 1", "Começo 2" e "Começo 3". Aqui, porém, o corpo é o meu corpo, revestido, protegido e delimitado pela "epiderme que por toda parte me recobre".

Por fragmentação, o corpo do sujeito se mostra, vindo à tona no discurso salvaguardado pelas referências dêiticas de primeira pessoa. Sob essa perspectiva, corrobora-se o caráter autobiográfico poético de Começo, em que "Escrever é pois 'mostrar-se', dar-se a ver, fazer aparecer o rosto próprio junto ao outro". ${ }^{20}$ Só que, ao mostrar-se, esse corpo se revela monstro (do latim, monstrare, 'mostrar'), desmontado e remontado em retalhos, incisões e costuras, as quais compõem um todo vacilante, que ameaça submergir novamente na indiferenciação do não eu, caso os fragmentos se separem novamente e o eu autobiográfico retorne à condição de um ele. Daí, o medo expresso na última frase de "Começo 4": "Devido ao nervo que o retém por detrás e que não vejo, há poucos riscos que meu olho caia". Ainda que improvável, o risco é nomeado porque é temido. Se cai o olho, que é por onde o sujeito vê o objeto e

\footnotetext{
${ }^{19}$ BARTHES. Variações sobre a escrita, p. 213.

${ }^{20}$ FOUCAULT. O que é um autor?, p. 8.
} 
dele se diferencia, mergulha o eu novamente em um não eu, instaurando um evento estranho a gênero autobiográfico: um "desnascimento".

\section{Considerações finais}

O espaço autobiográfico figurado no corpo composto, decomposto e recomposto nos textos da série "Começos", do livro homônimo de Quintane (2004), se constrói por um movimento de escrita que sugere a compreensão de um "si mesmo" por meio de anatomia e dissecação. Chama atenção, nos textos lidos, como o gênero autobiografia aqui se afasta de uma suposta verdade ou referencialidade e avança em uma desnaturalização poética da língua e do corpo a cada Começo.

Nesse processo, delineiam-se como linhas de força o erótico e o abjeto como instâncias em que o eu se reconhece - e se desafia como corpo e linguagem. Buscando os limites e a sintaxe do corpo para reconhecer a si, o sujeito poético aprende a dizer eu; por outro lado, ao virar seu dentro para fora nessa busca, expondo mucosas e orifícios, o sujeito está sob a ameaça de voltar a ser um não eu, derribando as frágeis fronteiras entre o mesmo e o outro, tão laboriosamente erigidas pelo ato autobiográfico.

Em síntese, como autobiografia e poesia, Começo propõe simultaneamente um percurso de formação e de deformação da primeira pessoa discursiva, como vias contrárias que se encontram no texto de Quintane. Nem da primeira à terceira pessoa, na proposição de Blanchot; nem da terceira à primeira pessoa, na proposição de Lejeune. Interessa aqui que, na proposição de Quintane, essa travessia é de mão dupla e interminável, deixando como rastro apenas um Começo de si.

\section{Referências}

ARFUCH, Leonor. O espaço biográfico: dilemas da subjetividade contemporânea. Rio de Janeiro: EDUERJ, 2010.

BARTHES, Roland. O prazer do Texto. Tradução de J. Guinsburg. São Paulo: Perspectiva, 1987.

BARTHES, Roland. Variações sobre a escrita. In: . Inéditos: teoria. São Paulo: Martins Fontes, 2004. v. 1. p. 174-253.

BLANCHOT, Maurice. O livro por vir. Lisboa: Relógio d'Água, 1984. 
BUTLER, Judith. Dar cuenta de sí mismo: violencia ética y responsabilidad. Buenos Aires: Amorrortu, 2009.

CALLIGARIS, Contardo. Verdades de autobiografias e diários íntimos. Revista de Estudos Históricos, Rio de Janeiro, v. 11, n. 21, p. 43-58, 1998. FOUCAULT, Michel. A escrita de si. In: . O que é um autor? Lisboa: Passagens. 1992. p. 129-160.

LEJEUNE, Philippe. O pacto autobiográfico: de Rousseau à internet. 2. ed. Belo Horizonte: Editora UFMG, 2014.

KRISTEVA, Julia. Introdução à semanálise. São Paulo: Perspectiva, 1974.

KRISTEVA, Julia. Powers of Horror: an Essay on Abjection. New York: Columbia University, 1982.

QUINTANE, Nathalie. Começo: [autobiografia]. Tradução de Paula Glenadel. São Paulo: Cosac Naify, 2004. (Coleção Ás de colete, v. 7)

Recebido em: 5 de dezembro de 2017. Aprovado em: 13 de março de 2018. 